\title{
Survey Article \\ THE TOWER OF HANOI PROBLEM AND ITS VARIANTS
}

\author{
A.A.K. Majumdar \\ APU, 1-1 Jumonjibaru, Beppu-shi 874-8577, Japan \\ Email : majumdar@apu.ac.jp
}

Received 02.12.2014

Accepted 18.08.2015

\begin{abstract}
The Tower of Hanoi is a popular mathematical puzzle, which appeared in 1885. During the past years, the problem has seen many variations. This paper reviews the Tower of Hanoi and its different variants. Some 3-peg variants are given in $\S 2, \S 3$ treats some 4-peg variants, $\S 4$ deals with the multi-peg generalization, and $\S 5$ gives some open problems.
\end{abstract}

Keywords : The Tower of Hanoi problem, 3-peg variants, 4-peg variants, multi-peg generalization

\section{Introduction}

The Tower of Hanoi is a popular mathematical puzzle, introduced by the famous French number theorist, Francois Edouard Anatole Lucas [9] in 1885.

The problem, in its general form, is as follows : Given are three pegs, $\mathrm{S}, \mathrm{P}$ and $\mathrm{D}$, and $\mathrm{n}(\geq 1)$ discs of different radii, labeled, $\mathrm{D}_{1}, \mathrm{D}_{2}, \ldots, \mathrm{D}_{\mathrm{n}}$ in increasing order. Initially, the $\mathrm{n}$ discs rest on the source peg $\mathrm{S}$, in a tower in small-on-large ordering, called the standard position, as shown in the figure below. A legal move is the transfer of exactly one (the topmost) disc on any peg to another under the "divine" rule that no disc can ever be placed on top of a smaller one. The objective is to transfer this tower of $\mathrm{n}$ discs from the peg, $\mathrm{S}$, to a standard tower on the destination peg, $\mathrm{D}$, in minimum number of legal moves, using all the pegs available.

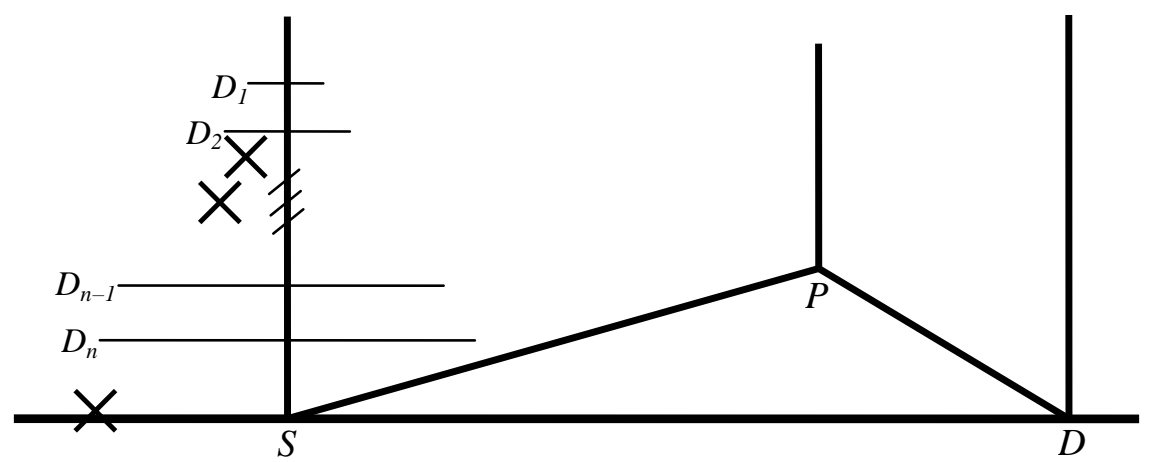

To solve the classical Tower of Hanoi problem, the scheme to be followed is

Step 1 : Move the topmost $\mathrm{n}-1$ discs from the source peg $\mathrm{S}$ to the auxiliary peg, $\mathrm{P}$, 
Step 2 : Shift the largest disc from the peg $S$ to destination peg D,

Step 3 : Transfer the tower of $\mathrm{n}-1$ discs from $\mathrm{P}$ to $\mathrm{D}$.

Denoting by $\mathrm{M}(\mathrm{n}, 3)$ the minimum number of moves required to solve the Tower of Hanoi with $\mathrm{n}$ discs, $M(n, 3)$ satisfies the recurrence relation :

$$
\mathrm{M}(\mathrm{n}, 3)=2 \mathrm{M}(\mathrm{n}-1,3)+1, \mathrm{n} \geq 1 ; \mathrm{M}(0,3)=0,
$$

whose solution is

$$
\mathrm{M}(\mathrm{n}, 3)=2^{\mathrm{n}}-1, \mathrm{n} \geq 1 .
$$

It has been shown by Wood [24] and Hinz [7] that the scheme followed is optimal, which is almost trivial from the scheme outlined above

In this paper, we review some of the variants of the Tower of Hanoi. Section 2 gives some 3-peg variants, some 4-peg variants are given in Section 3, Section 4 deals with the multi-peg generalization, and some open problems are given in the cocluding Section 5.

\section{3-peg Variants}

In this section, we consider five 3-peg variants of the Tower of Hanoi problem, treated in the following subsections.

\subsection{The Three-in-a-Row Puzzle}

The three-in-a-row puzzle, introduced by Scorer, Grundy and Smith [19], is as follows : The three pegs, S, P and D, are arranged in a row. Initially, a tower of $n(\geq 1)$ discs of different radii, labeled, $\mathrm{D}_{1}, \mathrm{D}_{2}, \ldots, \mathrm{D}_{\mathrm{n}}$, in increasing order of their radii, rest on the source peg, $\mathrm{S}$, in standard position, in small-on-large ordering. The objective is to transfer this tower from the peg, $S$, to the destination peg, $\mathrm{D}$, in standard position, in minimum number of moves under the additional condition that any (topmost) disc on a peg can be moved to an adjacent peg only.

Then, there are two possibilities, as shown in the figures below.

Let $\operatorname{MR}(\mathrm{n})$ and $\operatorname{MRR}(\mathrm{n})$ denote respectively the minimum number of moves required to shift the tower of $n(\geq 1)$ discs from the source peg, $S$, to the destination peg, $D$, corresponding to the cases (1) and (2) respectively in the figure.

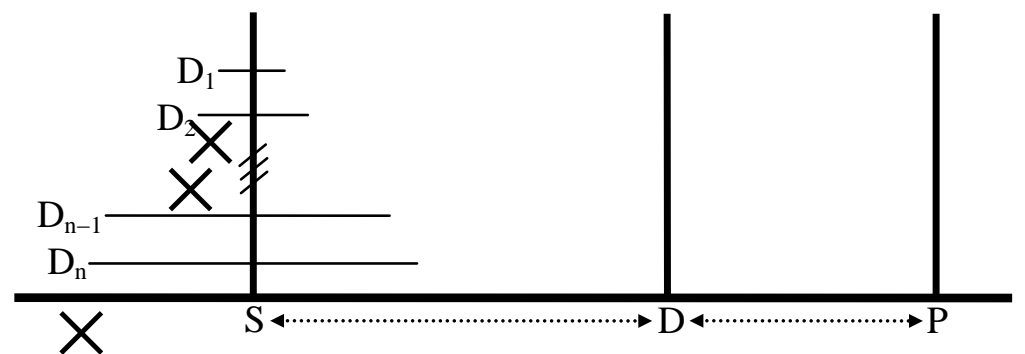

Case (1) : Disc movements are allowed between S, D, and D, P 


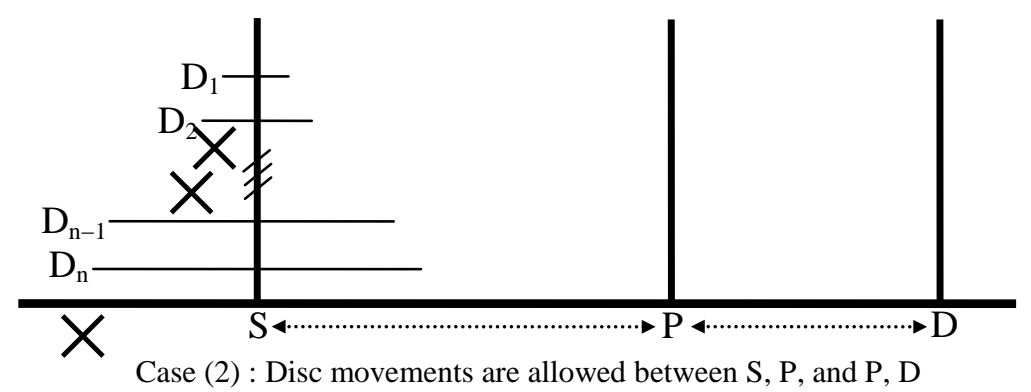

Lemma 2.1.1: $\operatorname{MR}(\mathrm{n})=3 \operatorname{MR}(\mathrm{n}-1)+1, \mathrm{n} \geq 1 ; \operatorname{MR}(0)=0$.

Lemma 2.1.2: $\operatorname{MRR}(\mathrm{n})=2 \operatorname{MR}(\mathrm{n})$ for all $\mathrm{n} \geq 1$.

The explicit form of MR(n) is given below.

Theorem 2.1.1: $\operatorname{MR}(\mathrm{n})=\frac{1}{2}\left(3^{\mathrm{n}}-1\right), \operatorname{MRR}(\mathrm{n})=3^{\mathrm{n}}-1, \mathrm{n} \geq 1$.

\subsection{The Cyclic Tower of Hanoi}

The cyclic Tower of Hanoi Problem, posed by Atkinson [1], is as follows : The three pegs, S, P and $\mathrm{D}$, are arranged in a circle. Initially, a tower of $\mathrm{n}(\geq 1)$ discs of different radii, designated as $\mathrm{D}_{1}, \mathrm{D}_{2}, \ldots, \mathrm{D}_{\mathrm{n}}$, in increasing order of their radii, rest on the source peg, $\mathrm{S}$, in standard position, in small-on-large ordering. The objective is to transfer this tower of $n$ discs from the peg, $\mathrm{S}$, to the destination peg, $\mathrm{D}$, in standard position, in minimum number of moves under the additional condition that, any (topmost) disc on a peg can be moved in the clockwise direction only.

Here also there are two possibilities, as shown in the figure below.
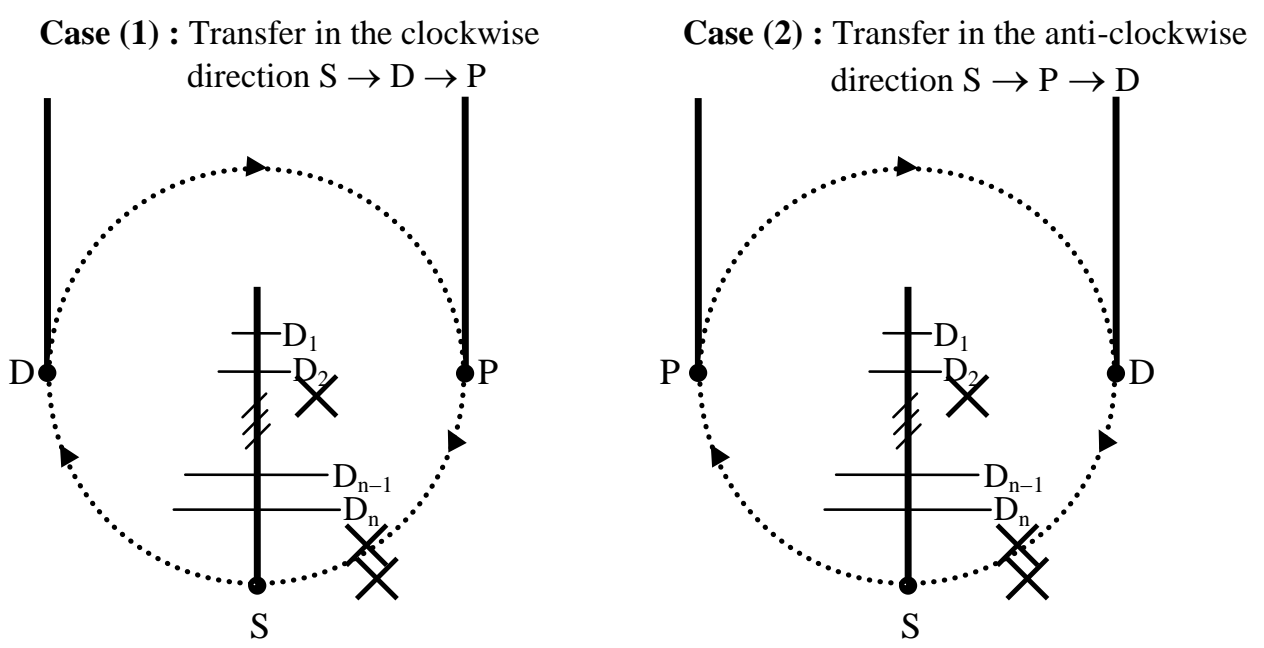

Let MC(n) and MA(n) denote respectively the minimum number of moves required to shift the tower of $\mathrm{n}(\geq 1)$ discs from the source peg, $\mathrm{S}$, to the destination peg, $\mathrm{D}$, corresponding to the Cases (1) and (2) respectively of the above figure. Then, we have the following results. 
Lemma 2.2.1 $: \mathrm{MC}(\mathrm{n})=\min \{2 \mathrm{MA}(\mathrm{n}-1)+1,4 \mathrm{MC}(\mathrm{n}-1)+1\} ; \mathrm{n} \geq 1, \mathrm{MC}(0)=0$.

Lemma 2.2.2: $\mathrm{MA}(0)=0$, and for $\mathrm{n} \geq 1$,

$\operatorname{MA}(n)=\min \{2 \operatorname{MA}(n-1)+\operatorname{MC}(n-1)+2,4 \operatorname{MA}(n-1)+2,5 \operatorname{MC}(n-1)+2\}$.

However, we have the following result :

Lemma 2.2.3 : For any $\mathrm{n} \geq 1$,

(1) $\mathrm{MC}(\mathrm{n})=2 \mathrm{MA}(\mathrm{n}-1)+1, \operatorname{MC}(0)=0$;

(2) $\operatorname{MA}(n)=2 M A(n-1)+M C(n-1)+2=M C(n)+M C(n-1)+1, \operatorname{MA}(0)=0$.

Explicit forms for MC(n) and MA(n), due to Atkinson [1], are given below.

Theorem 2.2.1: For $\mathrm{n} \geq 1$,

(1) $\mathrm{MC}(\mathrm{n})=\frac{1}{2 \sqrt{3}}\left[(1+\sqrt{3})^{\mathrm{n}+1}-(1-\sqrt{3})^{\mathrm{n}+1}\right]-1, \quad$ (2) $\mathrm{MA}(\mathrm{n})=\frac{1}{4 \sqrt{3}}\left[(1+\sqrt{3})^{\mathrm{n}+2}-(1-\sqrt{3})^{\mathrm{n}+2}\right]-1$.

\subsection{The Tower of Hanoi with Parallel Moves}

This variant of the Tower of Hanoi, posed and solved by Wu and Chen [25], is as follows : Given are the three pegs, $S, P$ and $D$, and $n(\geq 1)$ discs of different sizes, $D_{1}, D_{2}, \ldots, D_{n}$ (with $D_{n}$ being the largest, $\mathrm{D}_{\mathrm{n}-1}$ the second largest, and so on, with $\mathrm{D}_{1}$ being the smallest). Initially, the $\mathrm{n}$ discs rest on the source peg, $\mathrm{S}$, in a tower in standard position, in small-on-large ordering. The problem is to shift this tower of $\mathrm{n}$ discs from the peg $\mathrm{S}$ to the destination peg, $\mathrm{D}$, in standard position, in minimum number of moves, under the additional condition that each top disc may be simultaneously moved from its peg to another under the restriction that no more than one disc can be placed on the same peg.

(a)

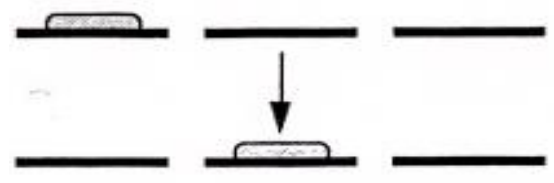

(c)

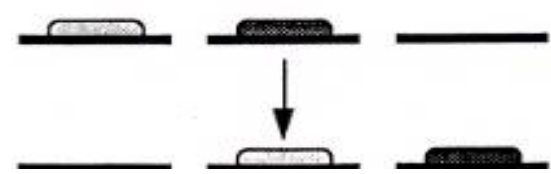

(b)

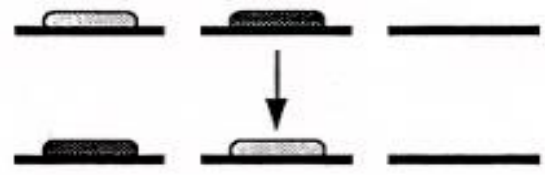

(d)

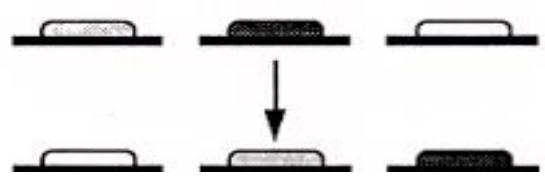

Figure : (a) single move, (b) exchange, (c) consecutive move, (d) circular move

In this case, four types of moves, namely, the single move, exchange, the consecutive move and the circular move, are allowed. 
Let MP(n) denote the minimum number of moves required to transfer the tower of $n$ discs in standard position, from $\mathrm{S}$ to $\mathrm{D}$, in the Tower of Hanoi with parallel moves. Then, MP(n) satisfies the following recursion formula, due to $\mathrm{Wu}$ and Chen [25], who have also proved the optimality of the scheme followed.

Lemma 2.3.1: $\mathrm{MP}(\mathrm{n})=2 \mathrm{MP}(\mathrm{n}-2)+1 ; \mathrm{n} \geq 4, \operatorname{MP}(1)=1, \operatorname{MP}(2)=3, \operatorname{MP}(3)=5$.

The explicit form of MP(n) is given below.

Theorem 2.3.1 : For $\mathrm{n} \geq 4$,

$$
\operatorname{MP}(n)= \begin{cases}2^{\frac{n+2}{2}}-1, & \text { if } n \text { is even } \\ 2^{\frac{n-1}{2}}-1, & \text { if } n \text { is odd }\end{cases}
$$

Table 2.1 : Values of $\mathrm{MP}(\mathrm{n})$ for $n=1(1) 10$

\begin{tabular}{|c|c|c|c|c|c|c|c|c|c|c|}
\hline $\mathrm{n}$ & 1 & 2 & 3 & 4 & 5 & 6 & 7 & 8 & 9 & 10 \\
\hline $\mathrm{MP}(\mathrm{n})$ & 1 & 3 & 5 & 7 & 11 & 15 & 23 & 31 & 47 & 63 \\
\hline
\end{tabular}

\subsection{The Tower of Hanoi with Cyclic Parallel moves}

The combination of the cyclic Tower of Hanoi, and the Tower of Hanoi with parallel moves, is the Tower of Hanoi with cyclic parallel moves, posed and solved by $\mathrm{Wu}$ and Chen [26], and may formally be stated as follows : Given are the three pegs, S, P and D, and n ( $\geq 1)$ discs of different sizes, $D_{1}, D_{2}, \ldots, D_{n}$ (with $D_{n}$ being the largest, $D_{n-1}$ the second largest, and so on, $D_{1}$ being the smallest). Initially, the $\mathrm{n}$ discs rest on the source peg, $\mathrm{S}$, in a tower in standard position. The problem is to shift this tower of $\mathrm{n}$ discs from the peg $\mathrm{S}$ to the destination peg, $\mathrm{D}$, in standard position, in minimum number of moves, under the additional condition that every topmost disc can be moved from its original peg to another peg in the clockwise direction $\mathrm{S} \rightarrow \mathrm{D} \rightarrow \mathrm{P} \rightarrow \mathrm{S}$ at a time. Thus, in this case the three types of moves allowed are single move, consecutive move and circular move.

Here, we have one of the two cases, shown in the figure below.

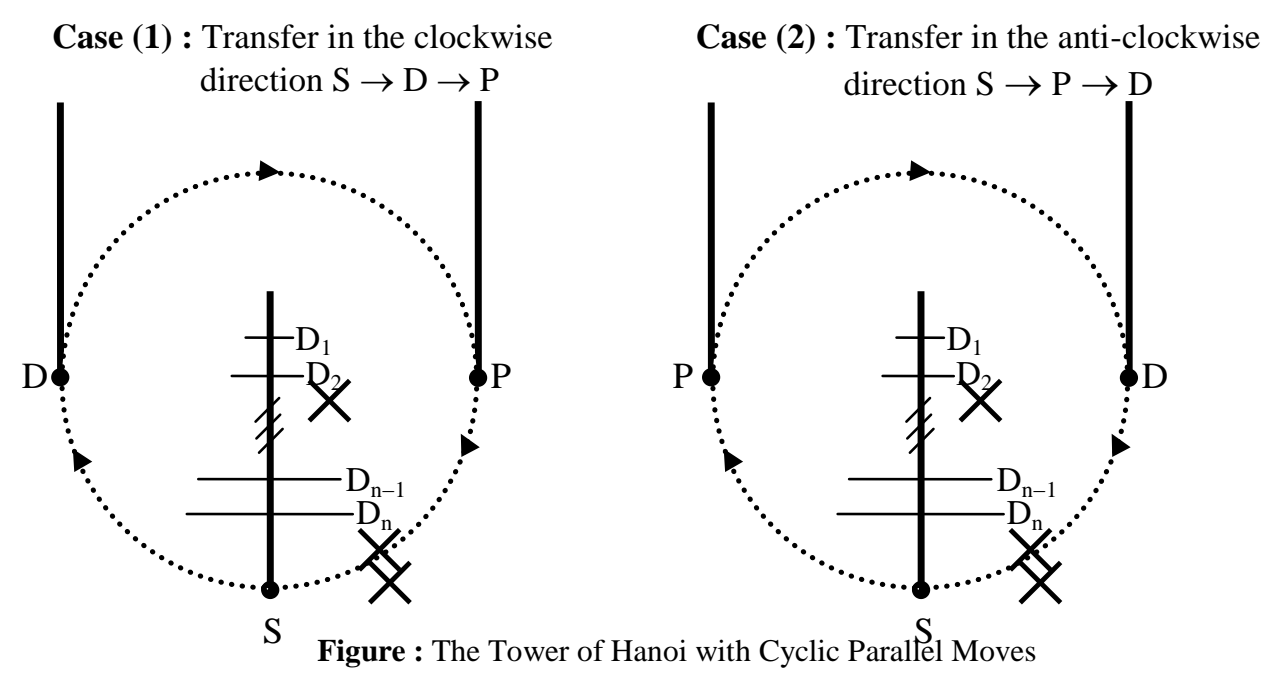


Let MPC(n) and MPA(n) denote respectively the minimum number of disc moves required to transfer the tower of $\mathrm{n}$ discs from $\mathrm{S}$ to $\mathrm{D}$, corresponding to the cases depicted in Cases (1) and (2) respectively. Then, MPC(n) and MPA(n) satisfy the following recurrence relations, established by Wu and Chen [26].

Lemma 2.4.1 : For $\mathrm{n} \geq 3$,

(1) $\operatorname{MPC}(n)=2 \operatorname{MPA}(n-1)-3($ with $\operatorname{MPC}(1)=1, \operatorname{MPC}(2)=4)$,

(2) $\operatorname{MPA}(n)=2 \operatorname{MPA}(n-1)+\operatorname{MPC}(n-1)-6($ with $\operatorname{MPA}(1)=2, \operatorname{MPA}(2)=5)$.

The explicit forms of MPC(n) and MPA(n), due to Wu and Chen [26], are given in the following

Theorem 2.4.1: For $\mathrm{n} \geq 3$,

(1) $\operatorname{MPC}(\mathrm{n})=\frac{1}{2}\left[(1+\sqrt{3})^{\mathrm{n}-1}+(1-\sqrt{3})^{\mathrm{n}-1}\right]+3$, (2) $\operatorname{MPA}(\mathrm{n})=\frac{1}{4}\left[(1+\sqrt{3})^{\mathrm{n}}+(1-\sqrt{3})^{\mathrm{n}}\right]+3$.

\subsection{Bottleneck Tower of Hanoi}

Poole [16] has considered a variation of the Tower of Hanoi, known as the bottleneck Tower of Hanoi. Actually, the idea of the bottleneck Tower of Hanoi was first introduced by Wood [24], and the problem treated by Poole [16] is only a slight modification of that problem.

Given any collection $\mathrm{C}$ of any number of discs, $\mathrm{D}_{\mathrm{i}}, \mathrm{D}_{\mathrm{j}}, \ldots, \mathrm{D}_{\mathrm{m}}$, the narrowness of $\mathrm{C}$, denoted by $\mathrm{N}(\mathrm{C})$, is the label-index of the smallest disc in $\mathrm{C}$, that is,

$$
\mathrm{N}(\mathrm{C})=\min \left\{\mathrm{i}: \mathrm{D}_{\mathrm{i}} \in \mathrm{C}\right\},
$$

with

$$
\mathrm{N}(\varnothing)=\infty(\varnothing \text { being the empty set }) .
$$

The bottleneck Tower of Hanoi is as follows : Given are the three pegs, S, P and D, and $\mathrm{n}(\geq 1)$ discs of different sizes, $D_{1}, D_{2}, \ldots, D_{n}$ (with $D_{n}$ being the largest, $D_{n-1}$ the second largest, and so on, with $\mathrm{D}_{1}$ being the smallest). Initially, the $\mathrm{n}$ discs rest on the source peg, $\mathrm{S}$, in a tower in standard position. The problem is to shift this tower of $\mathrm{n}$ discs from the peg $\mathrm{S}$ to the destination peg, $\mathrm{D}$, in standard position, in minimum number of moves, under the additional condition that a disc $\mathrm{D}_{\mathrm{i}}$ may not be placed on a tower of discs $\mathrm{T}$ if

$$
\mathrm{i}>\mathrm{N}(\mathrm{T})+\mathrm{b}-1 \text {, }
$$

where $\mathrm{b}(\geq 1)$ is a pre-assigned integer, called the bottleneck size.

Any arrangement of the $\mathrm{n}(\geq 1)$ discs on the three pegs that can be obtained without violating the condition of the bottleneck Tower of Hanoi, is called a legal position.

Now, given $\mathrm{n}(\geq 1)$ number of discs, the three pegs, S, P and D, and the bottleneck size $\mathrm{b}(\geq 1)$, let $\mathrm{g}_{3}(\mathrm{n}, \mathrm{b})$ denote the minimum number of moves required to transfer the tower of $\mathrm{n}$ discs from its starting position (not necessarily standard) to a legal (but not necessarily standard) position on 
another peg, and let $M_{3}(n, b)$ denote the minimum number of moves required to solve the bottleneck Tower of Hanoi problem. Then, $g_{3}(n, b)$ and $M_{3}(n, b)$ satisfy the following recurrence relations, due to Poole [16].

Lemma 2.5.1: For any $\mathrm{n}(\geq 1)$ and $\mathrm{b}(\geq 1)$,

(1) $g_{3}(n, b)=2 g_{3}(n-b, b)+b, n \geq b ; g_{3}(n, b)=n$ for all $0 \leq n \leq b$,

(2) $M_{3}(n, b)=2 g_{3}(n-1, b)+1, n \geq 1 ; M_{3}(0, b)=0$ for all $b \geq 1$.

The solution of the bottleneck Tower of Hanoi, giving explicit forms for $g_{3}(n, b)$ and $M_{3}(n, b)$, is given in the following theorem and corollary, due to Poole [16].

Theorem 2.5.1: Given $\mathrm{n}(\geq 1)$ and $\mathrm{b}(\geq 1)$, let $\mathrm{n}=\mathrm{bq}+\mathrm{r}, \mathrm{q} \in\{1,2, \ldots\}, 0 \leq \mathrm{r}<\mathrm{b}$.

Then,

(1) $g_{3}(n, b)=(b+r) 2^{q}-b$,

(2) $M_{3}(n, b)= \begin{cases}(2 b-1)\left(2^{q}-1\right), & \text { if } r=0 \\ (b+r-1) 2^{q+1}-2 b+1, & \text { if } r \neq 0\end{cases}$

Corollary 2.5.1: For $\mathrm{n} \geq 1, \mathrm{~g}_{3}(\mathrm{n}, 2)= \begin{cases}2\left(2^{\frac{\mathrm{n}}{2}}-1\right), & \text { if } \mathrm{n} \text { is even } \\ 3.2^{\frac{\mathrm{n}-1}{2}}-1, & \text { if } \mathrm{n} \text { is odd }\end{cases}$

\subsection{The Little Tower of Antwerpen}

The problem, due to Minsker [14], is as follows : Two identical towers, one consisting of $n$ black discs (of different radii) and the other consisting of $n(\geq 1)$ red discs, rest on two pegs $\mathrm{P}_{1}$ and $\mathrm{P}_{2}$ respectively (in small-on-large ordering). The situation is shown schematically below where $B_{i}=$ $\mathrm{R}_{\mathrm{i}}$ for all $1 \leq \mathrm{i} \leq \mathrm{n}$.

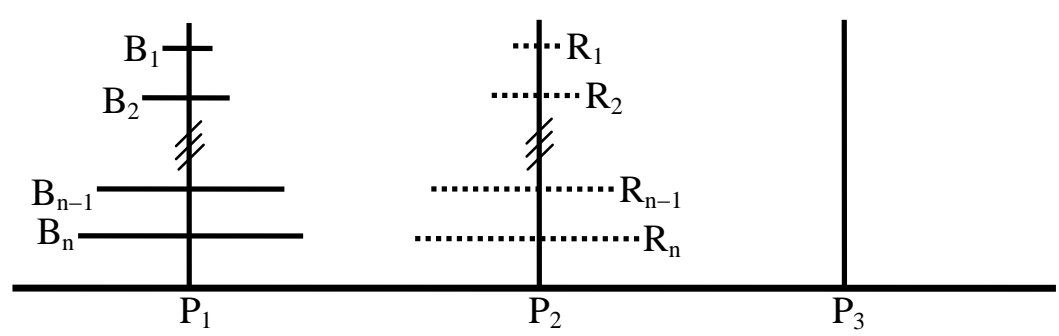

The objective is to interchange the two towers on $\mathrm{P}_{1}$ and $\mathrm{P}_{2}$, using the peg $\mathrm{P}_{3}$, in minimum number of moves, obeying the rules of the classical Tower of Hanoi.

Denoting by LAM(n) the minimum number of moves required, we have 
$\operatorname{LAM}(n)= \begin{cases}\frac{1}{3}\left(7.2^{n+1}-9 n-11\right), & \text { if } n \text { is even } \\ \frac{1}{3}\left(7.2^{n+1}-9 n-10\right), & \text { if } n \text { is odd }\end{cases}$

\subsection{The Tower of Antwerpen}

In the Tower of Antwerpen, introduced by Wood [23], three identical towers of $n(\geq 1)$ discs (of different sizes) of three different colors, black, red and white, rest on the three pegs $\mathrm{P}_{1}, \mathrm{P}_{2}$ and $\mathrm{P}_{3}$ respectively, where $B_{i}=R_{i}=W_{i}$ for all $1 \leq i \leq n$.

The objective is to transfer the towers of black, red and white discs (on the pegs $\mathrm{P}_{1}, \mathrm{P}_{2}$ and $\mathrm{P}_{3}$ respectively) to the pegs $\mathrm{P}_{2}, \mathrm{P}_{3}$ and $\mathrm{P}_{1}$ respectively, in minimum number of moves, without violating the conditions of the classical Tower of Hanoi.

Denoting by $\operatorname{AM}(n)$ the minimum number of moves required, the expression for $A M(n)$, due to Minsker [15], is as follows :

$$
\operatorname{AM}(n)=3.2^{n+2}-8 n-10, n \geq 2 ; \operatorname{AM}(1)=5 .
$$

\section{4-peg Variants}

In this section, we consider three 4-peg variants of the Tower of Hanoi.

\subsection{The Reve's Puzzle}

The Reve's puzzle is the 4-peg version of the Tower of Hanoi, and was considered by Lucas [10] and Dudeney [2]. Later, the problem was revived by Roth [18].

The problem is as follows : There are four pegs, $S, P_{1}, P_{2}$, and D. Initially, the $n(\geq 1)$ discs rest on the source peg, $\mathrm{S}$, in a tower in small-on-large ordering. The problem is to shift the tower from $\mathrm{S}$ to the destination peg $\mathrm{D}$, in standard position, in minimum number of moves, under the conditions of the Tower of Hanoi.

\subsection{The Star Puzzle}

The star puzzle, introduced by Stockmeyer [21] is a variant of the Tower of Hanoi, where there is a fourth peg such that all disc movements are either to or from the fourth peg.

More precisely, the star puzzle may be stated as follows: The three pegs, S, P and D, are arranged in an equilateral triangle, and the fourth peg is at the center 0 . Each disc movement must be either to or from 0 , that is, direct moves of discs between any two of the pegs S, P and D are not allowed. Initially, the $n$ discs, $D_{1}, D_{2}, \ldots, D_{n}$, of different sizes, are placed on the source peg, $S$, in a tower in standard position. The problem is to shift this tower of $n(\geq 1)$ discs from the source peg, $S$, to the destination peg, $\mathrm{D}$, in standard position, in minimum number of moves, under the conditions of the Tower of Hanoi.

The situation is depicted below. 


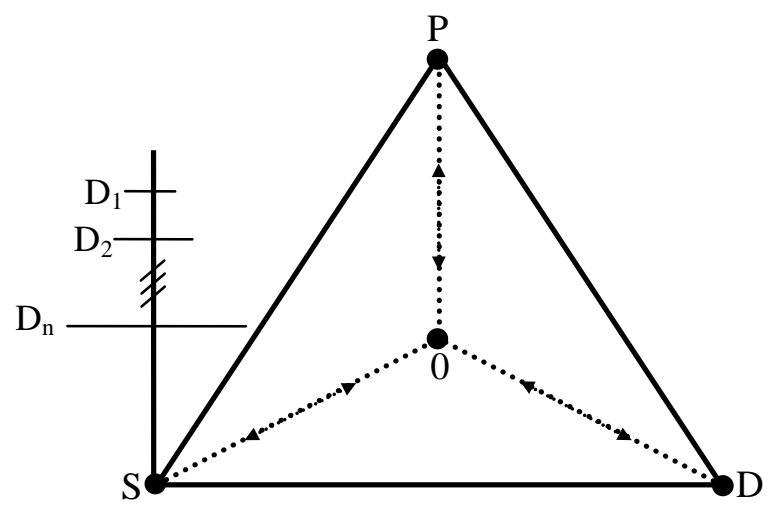

Figure : The Star Puzzle.

Let MS(n) denote the minimum number of moves required. Then, MS(n) satisfies the following dynamic programming equation due to Stockmeyer [21].

Lemma 3.2.1: For $\mathrm{n} \geq 2$,

$$
\begin{aligned}
\operatorname{MS}(n)= & \min \left\{2 \operatorname{MS}(n-k)+3^{k}-1\right\}, \\
& 1 \leq \mathrm{k} \leq \mathrm{n}-1 \\
\operatorname{MS}(0)= & 0, \operatorname{MS}(1)=2 .
\end{aligned}
$$

Theorem 3.2.1: Let $\left\{\mathrm{a}_{\mathrm{m}}\right\}_{\mathrm{m}=1}^{\infty}$ be the sequence of integers in increasing order :

$a_{m}=2^{i} 3^{j}, i \geq 0, j \geq 0$,

(so that, $\left\{\mathrm{a}_{\mathrm{m}}\right\}$ is the sequence $\left.\left\{1,2,3,2^{2}, 2.3,2^{3}, 3^{2}, 3.2^{2}, 2^{4}, 2.3^{2}, 3.2^{3}, \ldots\right\}\right)$. Then, $\mathrm{k}^{*}=\mathrm{k}^{*}(\mathrm{n})$, minimizing the right-hand side of (3.2.1), and $\mathrm{MS}(\mathrm{n})$ are given by

$\mathrm{k}^{*}=\mathrm{k}^{*}(\mathrm{n})=\left\lfloor\log _{3}\left(\mathrm{a}_{\mathrm{n}}\right)\right\rfloor+1 ; \operatorname{MS}(\mathrm{n})=2 \sum_{\mathrm{m}=1}^{\mathrm{n}} \mathrm{a}_{\mathrm{m}}$.

The table below reproduces the values of $\operatorname{MS}(n)$ and $k^{*}$ for some small values of $n$.

Table 3.1 : Values of MS(n) and $k^{*}=k^{*}(n)$ for $n=1(1) 12$

\begin{tabular}{|l|l|l|l|l|l|l|l|l|l|l|l|l|}
\hline $\mathrm{n}$ & 1 & 2 & 3 & 4 & 5 & 6 & 7 & 8 & 9 & 10 & 11 & 12 \\
\hline $\mathrm{MS}(\mathrm{n})$ & 2 & 6 & 12 & 20 & 32 & 48 & 66 & 90 & 122 & 158 & 206 & 260 \\
\hline $\mathrm{k}^{*}$ & 1 & 1 & 2 & 2 & 2 & 2 & 3 & 3 & 3 & 3 & 3 & 4 \\
\hline
\end{tabular}

\subsection{2-Color Puzzles}

Stockmeyer and Lunnon [22] have introduced two new variations of the 4-peg Tower of Hanoi, each with two towers of $\mathrm{n}(\geq 1)$ discs, where the two sets of discs are identical in size and differ only in color. The first puzzle is known as the 2-color Reve's puzzle, while the second one is known as the turtle. The two puzzles are given below. 


\subsubsection{The 2-Color Reve's Puzzle}

The puzzle is as follows : There are four pegs, $S_{B}, S_{R}, P_{1}$ and $P_{2}$. Initially, $n(\geq 1)$ black discs, $B_{1}$, $B_{2}, \ldots, B_{n}$, are placed on the peg, $S_{B}$, in a tower in standard position. The second tower of $n$ red discs, $R_{1}, R_{2}, \ldots, R_{n}$, rest on the peg $S_{B}$, in standard position. Thus, schematically, we have the following situation at the start :

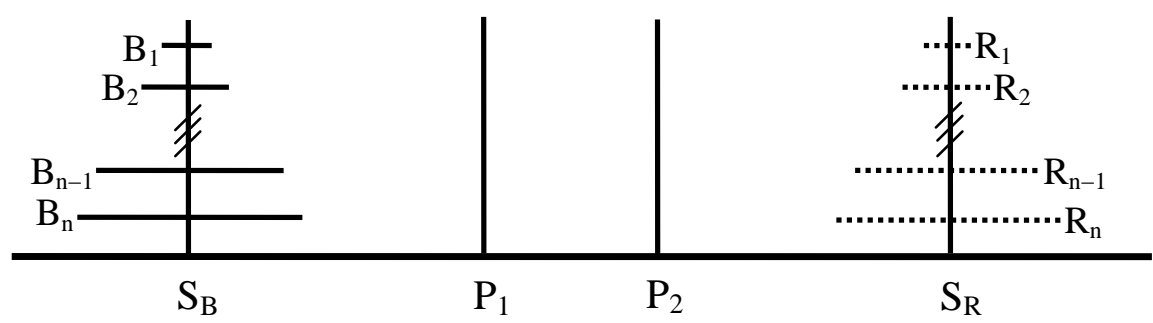

Figure : The 2-Color Reve's Puzzle

The problem is to interchange the towers on $S_{B}$ and $S_{R}$, using the auxiliary pegs, $P_{1}$ and $P_{2}$, in minimum number of moves, under the conditions of the Tower of Hanoi. Thus, a disc can be placed on an empty peg, or on top of a larger disc of any color.

Denoting by MCR(n) the minimum number of moves required to solve the above puzzle, the explicit form of $\operatorname{MCR}(\mathrm{n})$ is given in the following theorem.

Theorem 3.3.1.1: $\operatorname{MCR}(\mathrm{n})=2^{\mathrm{n}+1}-1$ for all $\mathrm{n} \geq 1$.

\subsubsection{The Turtle}

The turtle, as it is sometimes called, is as follows : There are four pegs, $S_{B}, S_{R}, P_{1}$ and $P_{2}$. Initially, $\mathrm{n}(\geq 1)$ black discs, $\mathrm{B}_{1}, \mathrm{~B}_{2}, \ldots, \mathrm{B}_{\mathrm{n}}$, are placed on the peg, $\mathrm{S}_{\mathrm{B}}$, in a tower in standard position. The second tower of $n$ red discs, $R_{1}, R_{2}, \ldots, R_{n}$, rest on the peg $S_{B}$, in standard position. The problem is to shift the tower of $n$ black discs from the peg $S_{B}$ to the peg $S_{R}$, and the tower of $n$ red discs from the peg $S_{R}$ to the peg $S_{B}$, using the auxiliary pegs, $P_{1}$ and $P_{2}$, in minimum number of moves, under the additional condition that the auxiliary peg $\mathrm{P}_{1}$ can hold only the black discs, while the other auxiliary peg $\mathrm{P}_{2}$ can hold only the red discs.

Let MT(n) be the minimum number of moves required to solve the turtle. Then, we have the following result :

Theorem 3.3.2.1 $: \operatorname{MT}(\mathrm{n})=3\left(2^{\mathrm{n}}-1\right)$ for all $\mathrm{n} \geq 1$.

\section{Multi-Peg Generalization}

The multi-peg generalization of the Tower of Hanoi, involving $n(\geq 1)$ discs and $p(\geq 4)$ pegs, was posed by Stewart [20]. Two solutions, giving the minimum number of moves required, were given, one by Stewart himself, and the second one by Frame [3]. 
The problem is as follows: Given are $\mathrm{p}(\geq 4)$ pegs, $S, \mathrm{P}_{1}, \ldots, \mathrm{P}_{\mathrm{p}-2}, \mathrm{D}$, and $\mathrm{n}(\geq 1)$ discs of different radii. Initially, the $\mathrm{n}$ discs rest on the source peg, $\mathrm{S}$, in a tower in standard position. The problem is to shift the tower from the peg $\mathrm{S}$ to the destination peg, $\mathrm{D}$, in standard position, in minimum number of moves, under the conditions of the Tower of Hanoi.

To move the tower from the peg $\mathrm{S}$ to the peg $\mathrm{D}$, the scheme followed is as follows :

Step 1: First, move the topmost k (consecutive) discs from the peg $\mathrm{S}$ to some auxiliary peg, say, $\mathrm{P}_{1}$, using all the $\mathrm{p}$ pegs available, in (minimum) $\mathrm{M}(\mathrm{k}, \mathrm{p})$ number of moves,

Step 2: Next, shift the remaining $\mathrm{n}-\mathrm{k}$ (consecutive) discs from the peg $\mathrm{S}$ to the peg $\mathrm{D}$, using the $\mathrm{p}-1$ pegs, which involves (minimum) $\mathrm{M}(\mathrm{n}-\mathrm{k}, \mathrm{p}-1)$ number of moves,

Step 3 : Finally, move the $\mathrm{k}$ discs from the peg $\mathrm{P}_{1}$ on top of the $\mathrm{n}-\mathrm{k}$ discs on the peg $\mathrm{D}$.

Thus, letting M(n, p) be the minimum number of moves required to solve the problem, the above scheme leads to the following proposition.

Proposition 4.1 : For all $\mathrm{n} \geq \mathrm{p} \geq 4$,

$$
\begin{aligned}
\mathrm{M}(\mathrm{n}, \mathrm{p})= & \min \{2 \mathrm{M}(\mathrm{k}, \mathrm{p})+\mathrm{M}(\mathrm{n}-\mathrm{k}, \mathrm{p}-1)\}, \\
& 0 \leq \mathrm{k} \leq \mathrm{n}-1
\end{aligned}
$$

$\mathrm{M}(0, \mathrm{p})=0$ for all $\mathrm{p} \geq 3 ; \mathrm{M}(\mathrm{n}, \mathrm{p})=2 \mathrm{n}-1$ if $1 \leq \mathrm{n} \leq \mathrm{p}-1, \mathrm{p} \geq 3$.

We define the optimal partition numbers, $\mathrm{k}_{\min }(\mathrm{n}, \mathrm{p})$ and $\mathrm{k}_{\max }(\mathrm{n}, \mathrm{p})$, as follows :

$$
\begin{aligned}
& \mathrm{k}_{\text {min }}(\mathrm{n}, \mathrm{p})=\min \{\mathrm{k}: 0 \leq \mathrm{k} \leq \mathrm{n}-1, \mathrm{M}(\mathrm{n}, \mathrm{p})=2 \mathrm{M}(\mathrm{k}, \mathrm{p})+\mathrm{M}(\mathrm{n}-\mathrm{k}, \mathrm{p}-1)\}, \\
& \mathrm{k}_{\max }(\mathrm{n}, \mathrm{p})=\max \{\mathrm{k}: 0 \leq \mathrm{k} \leq \mathrm{n}-1, \mathrm{M}(\mathrm{n}, \mathrm{p})=2 \mathrm{M}(\mathrm{k}, \mathrm{p})+\mathrm{M}(\mathrm{n}-\mathrm{k}, \mathrm{p}-1)\}, \\
& \mathrm{k}_{\min }(1, \mathrm{p})=0=\mathrm{k}_{\max }(1, \mathrm{p}) \text { for all } \mathrm{p} \geq 4, \\
& \mathrm{k}_{\min }(\mathrm{n}, \mathrm{p})=0, \mathrm{k}_{\max }(\mathrm{n}, \mathrm{p})=1 \text { for } 2 \leq \mathrm{n} \leq \mathrm{p}-2, \mathrm{p} \geq 4, \\
& \mathrm{k}_{\min }(\mathrm{p}-1, \mathrm{p})=1=\mathrm{k}_{\max }(\mathrm{p}-1, \mathrm{p}) \text { for all } \mathrm{p} \geq 4 .
\end{aligned}
$$

The solution of the multi-peg Tower of Hanoi is given in the theorem below.

Theorem 4.1: For the p-peg Tower of Hanoi problem with $\mathrm{p} \geq 4$, let

$$
\begin{array}{r}
\left(\begin{array}{c}
\mathrm{p}+\mathrm{s}-3 \\
\mathrm{p}-2
\end{array}\right)<\mathrm{n} \leq\left(\begin{array}{c}
\mathrm{p}+\mathrm{s}-2 \\
\mathrm{p}-2
\end{array}\right)-1 \text { for some } \mathrm{s} \in\{1,2, \ldots\} ; \\
\mathrm{R}=\mathrm{n}-\left(\begin{array}{c}
\mathrm{p}+\mathrm{s}-3 \\
\mathrm{p}-2
\end{array}\right) \quad\left(\text { so that } 1 \leq \mathrm{R} \leq\left(\begin{array}{c}
\mathrm{p}+\mathrm{s}-3 \\
\mathrm{p}-3
\end{array}\right)-1\right)
\end{array}
$$


Then,

(a) $\mathrm{k}_{\min }(\mathrm{n}, \mathrm{p})= \begin{cases}\left(\begin{array}{c}\mathrm{p}+\mathrm{s}-4 \\ \mathrm{p}-2\end{array}\right), & \text { if } 1 \leq \mathrm{R} \leq\left(\begin{array}{c}\mathrm{p}+\mathrm{s}-4 \\ \mathrm{p}-4\end{array}\right) \\ \mathrm{n}-\left(\begin{array}{c}\mathrm{p}+\mathrm{s}-3 \\ \mathrm{p}-3\end{array}\right), & \text { if }\left(\begin{array}{c}\mathrm{p}+\mathrm{s}-4 \\ \mathrm{p}-4\end{array}\right) \leq \mathrm{R} \leq\left(\begin{array}{c}\mathrm{p}+\mathrm{s}-3 \\ \mathrm{p}-3\end{array}\right)-1\end{cases}$

(b) $\mathrm{k}_{\max }(\mathrm{n}, \mathrm{p})= \begin{cases}\mathrm{n}-\left(\begin{array}{c}\mathrm{p}+\mathrm{s}-4 \\ \mathrm{p}-3\end{array}\right), & \text { if } 1 \leq \mathrm{R} \leq\left(\begin{array}{c}\mathrm{p}+\mathrm{s}-4 \\ \mathrm{p}-3\end{array}\right) \\ \left(\begin{array}{c}\mathrm{p}+\mathrm{s}-3 \\ \mathrm{p}-2\end{array}\right), & \text { if }\left(\begin{array}{c}\mathrm{p}+\mathrm{s}-4 \\ \mathrm{p}-3\end{array}\right) \leq \mathrm{R} \leq\left(\begin{array}{c}\mathrm{p}+\mathrm{s}-3 \\ \mathrm{p}-3\end{array}\right)-1\end{cases}$

(c) $\mathrm{M}(\mathrm{n}, \mathrm{p})=\sum_{\mathrm{t}=0}^{\mathrm{s}-1} 2^{\mathrm{t}}\left(\begin{array}{c}\mathrm{p}+\mathrm{t}-3 \\ \mathrm{p}-3\end{array}\right)+2^{\mathrm{s}}\left\{\mathrm{n}-\left(\begin{array}{c}\mathrm{p}+\mathrm{s}-3 \\ \mathrm{p}-2\end{array}\right)\right\}$.

$\mathrm{M}(\mathrm{n}, \mathrm{p})$, given in the above theorem, is called the presumed minimum solution. Note that, the Reve's puzzle is a particular case of the multi-peg generalization. Another variant is given in the following subsection.

\subsection{The 2-Color 5-Peg Puzzle}

The puzzle, due to Stockmeyer and Lunnon [22], is as follows : There are five pegs, $S_{B}, S_{R}, P_{1}, P_{2}$ and $P_{3}$. Initially, $n(\geq 1)$ black discs, $B_{1}, B_{2}, \ldots, B_{n}$, are placed on the peg, $S_{B}$, in a tower in standard position. The second tower of $n$ red discs, $R_{1}, R_{2}, \ldots, R_{n}$ (with $R_{i}$ of the same size as that of $B_{i}$ for all $1 \leq i \leq n$ ) rest on the peg $S_{B}$, in standard position.

The problem is to shift the tower of $n$ black discs from the peg $S_{B}$ to the peg $S_{R}$, and the tower of $n$ red discs from the peg $S_{R}$ to the peg $S_{B}$, using the auxiliary pegs $P_{1}, P_{2}$ and $P_{3}$, in minimum number of moves, under the conditions of the Tower of Hanoi, together with the additional condition that the black discs can use the pegs $\mathrm{S}_{\mathrm{B}}, \mathrm{P}_{1}, \mathrm{P}_{3}$ and $\mathrm{S}_{\mathrm{R}}$ only, while the red discs can use the pegs $\mathrm{S}_{\mathrm{R}}, \mathrm{P}_{2}$, $\mathrm{P}_{3}$ and $\mathrm{S}_{\mathrm{B}}$ only for disc movements.

Let MRR(n) be the minimum number of moves required to solve the above puzzle. The explicit form of MRR(n) is given in the theorem below.

Theorem 4.1.1 $: \operatorname{MRR}(\mathrm{n})=\mathrm{M}(\mathrm{n}, 4)+2^{\mathrm{n}}$ for all $\mathrm{n} \geq 1$.

Consider the unrestricted problem where a disc of either color can be placed on any peg. Denoting by MRU(n) the minimum number of moves required to solve this problem, we have the following theorem :

Theorem 4.1.2: MRU(n) $=M(n, 4)+2 M(n-1,4)+2$ for all $n \geq 1$.

The explicit form of MRU(n) is given in the following theorem, where $\mathrm{k}$ is the value for which $\mathrm{M}(\mathrm{n}, 4)$ is attained. 
Theorem 4.1.3: If $\frac{\mathrm{s}(\mathrm{s}+1)}{2} \leq \mathrm{n} \leq \frac{(\mathrm{s}+1)(\mathrm{s}+2)}{2}-1$ for some $\mathrm{s} \geq 1$, then

$\operatorname{MRU}(n)=2^{s-1}\{6 n-3 s(s-1)-10\}+5, \quad k=\left\{\begin{array}{l}\frac{s(s-1)}{2}, \text { if } n=\frac{s(s+1)}{2} \\ n-s-1, \text { otherwise }\end{array}\right.$

The values of MRR(n) and MRU(n) for some small values of $\mathrm{n}$ are given below.

Table 4.1 : Values of MRR(n) and MRU(n) for $n=1(1) 10$

\begin{tabular}{|l|l|l|l|l|l|l|l|l|l|l|}
\hline $\mathrm{n}$ & 1 & 2 & 3 & 4 & 5 & 6 & 7 & 8 & 9 & 10 \\
\hline MRR(n) & 3 & 7 & 13 & 25 & 45 & 81 & 153 & 289 & 553 & 1073 \\
\hline MRU(n) & 3 & 7 & 13 & 21 & 33 & 45 & 61 & 85 & 109 & 133 \\
\hline
\end{tabular}

We conclude this paper with some open problem related the Tower of Hanoi. These are given in the next section.

\section{Some Open Problems}

In this section, some open problems related to the Tower of Hanoi are considered. These are given in the following four subsections.

\subsection{Problems Remaining Unresolved for the p-Peg Tower of Hanoi}

First, we give two problems, related to the p-peg Tower of Hanoi, that are open. The first one is the so-called Frame's conjecture. The second problem is related to the computational aspects of the Tower of Hanoi problem.

\subsubsection{Frame's Conjecture}

In the dynamic programming formulation of the p-peg $(p \geq 3)$ Tower of Hanoi, in moving a tower of $\mathrm{n}(\geq 1)$ discs from the source peg, $\mathrm{S}$, to the destination peg, $\mathrm{D}$, the tower of the smallest $\mathrm{n}-1$ discs is dismantled into $p-2$ number of subtowers of consecutive discs, which are then moved to the $p-2$ auxiliary pegs. This procedure rests on the assumption that, at least one of the shortest routes leads to a position in which all the other pegs have towers of consecutive discs on them. Donald Knuth christened this as "Frame's conjecture" (Lunnon [11]). This is the reason that, some authors prefer to call the minimum number of moves given by the dynamic programming equation the presumed minimum solution (pms) (Hinz [6]).

For the 4-peg Tower of Hanoi, Majumdar [13] has shown that, the scheme leading to the dynamic programming equation is optimal and unique for $\mathrm{n} \geq 6$, and further that, for $n=4,5$, the scheme is at least as good as any other scheme generating the minimum number of moves. For $n=4$, there is an alternative scheme which is not pms, and for $\mathrm{n}=5$, there are two alternative schemes, in addition to the pms.

For the p-peg Tower of Hanoi with $\mathrm{p} \geq 5$, it remains to resolve Frame's conjecture. 
We conjecture that, for "large" values of $n$, the pms is the only optimal solution. The conjecture is based on the fact that, for $\mathrm{p}=4$, the pms is the only optimal solution for $\mathrm{n} \geq 6$.

\subsubsection{Recursion versus Iteration}

From the theoretical point of view, the p-peg $(p \geq 4)$ Tower of Hanoi is solved if one knows the expressions for $M(n, p)$ as well as $k_{\min }(n, p)$ and $k_{\max }(n, p)$ (given in Theorem 4.1 in $\S 4$ ). However, in computer science and programming, one is interested in generating the moves of the individual discs, and to devise an optimal algorithm that generates the minimum number of moves (Rohl and Gedeon [17]).

For the 3-peg Tower of Hanoi, a recursive algorithm is given in Majumdar [13]. An iterative algorithm, which is more efficient than the recursive one, both in time and memory requirements, has been offered by Hayes [5], and has been reproduced in Algorithm 1.2 in Majumdar [13].

For the generalized p-peg Tower of Hanoi problem with $n(\geq 1)$ discs, Majumdar [13] gives both recursive and iterative algorithms. An iterative algorithm for the 4-peg Tower of Hanoi (Reve's puzzle), based on the divide-and-conquer approach, has been offered by van de Liefvoort [8], where the tower of $\mathrm{n}(\geq 1)$ discs on the source peg is divided into subtowers, each of which, viewed as a single entity, is then moved in an iterative algorithm of the 3-peg Tower of Hanoi. The divide-and-conquer approach can be extended to the $\mathrm{p}$-peg case with $\mathrm{p} \geq 5$, where the tower of $n$ $(\geq 1)$ discs on the source peg is divided into slices, each viewed as a single entity, can then be moved in an algorithm of the ( $\mathrm{p}-1)$-peg problem. Besides this, there are iterative algorithms due to Hinz [6], Lu [12] and Gedeon [4].

For the p-peg problem with $\mathrm{p} \geq 5$, no iterative algorithm has yet been devised.

\subsection{The Bottleneck Reve's Puzzle}

The generalization of the 3-peg bottleneck Tower of Hanoi to four pegs may be called the bottleneck Reve's puzzle.

Initially, the $n(\geq 1)$ discs, $D_{1}, D_{2}, \ldots, D_{n}$ of varying sizes, rest on the source peg, $S$, in standard position. The problem is to shift this tower from the peg $S$ to the destination peg, $D$, in standard position, in minimum number of moves, under the additional condition that a disc $\mathrm{D}_{\mathrm{i}}$ may not be placed on a tower of discs $\mathrm{T}$ if

$$
\mathrm{i}>\mathrm{N}(\mathrm{T})+\mathrm{b}-1 \text {. }
$$

Given $\mathrm{n}(\geq 1)$ and $\mathrm{b}(\geq 1)$, let $\mathrm{g}_{4}(\mathrm{n}, \mathrm{b})$ be the minimum number of moves required to shift the tower of $\mathrm{n}$ discs from its starting position to a legal position (not necessarily, standard) on another peg (using all the four pegs); also, let $\mathrm{M}_{4}(\mathrm{n}, \mathrm{b})$ be the minimum number of moves required to solve the bottleneck Reve's puzzle. Then, the dynamic programming equations satisfied by $\mathrm{g}_{4}(\mathrm{n}, \mathrm{b})$ and $\mathrm{M}_{4}(\mathrm{n}, \mathrm{b})$ are given in Lemma 5.2.1 and Lemma 5.2.2 respectively.

Lemma 5.2.1 : For $\mathrm{n}(\geq 1)$ and $\mathrm{b}(\geq 1)$, 


$$
\begin{aligned}
g_{4}(n, b)= & \min 2\left\{g_{4}(k, b)+g_{3}(n-b-k, b)\right\}+b, n \geq b, \\
& 1 \leq k \leq n-b
\end{aligned}
$$

$\mathrm{g}_{4}(\mathrm{n}, \mathrm{b})=\mathrm{n}$ for all $0 \leq \mathrm{n} \leq \mathrm{b}$.

Lemma 5.2.2 : For $\mathrm{n}(\geq 1)$ and $\mathrm{b}(\geq 1)$,

$$
\begin{aligned}
M_{4}(n, b)= & \min 2\left\{g_{4}(\ell, b)+g_{3}(n-\ell-1, b)\right\}+1, n \geq 1, \\
& 1 \leq \ell \leq n-1
\end{aligned}
$$

$\mathrm{M}_{4}(0, \mathrm{~b})=0$ for all $\mathrm{b} \geq 1$.

For $\mathrm{n}(\geq 1)$ and $\mathrm{b}(\geq 1)$ fixed, let

$\mathrm{G}(\mathrm{n}, \mathrm{k}, \mathrm{b})=2\left\{\mathrm{~g}_{4}(\mathrm{k}, \mathrm{b})+\mathrm{g}_{3}(\mathrm{n}-\mathrm{b}-\mathrm{k}, \mathrm{b})\right\}+\mathrm{b} ; 0 \leq \mathrm{k} \leq \mathrm{n}-\mathrm{b}$,

$\mathrm{F}(\mathrm{n}, \ell, \mathrm{b})=2\left\{\mathrm{~g}_{4}(\ell, \mathrm{b})+\mathrm{g}_{3}(\mathrm{n}-\ell-1, \mathrm{~b})\right\}+1 ; 0 \leq \ell \leq \mathrm{n}-1$.

Furthermore, let

$\mathrm{k}_{\min }(\mathrm{n}, \mathrm{b})=\min \left\{\mathrm{k}: 0 \leq \mathrm{k} \leq \mathrm{n}-\mathrm{b}, \mathrm{g}_{4}(\mathrm{n}, \mathrm{b})=\mathrm{G}(\mathrm{n}, \mathrm{k}, \mathrm{b})\right\}$,

$\mathrm{k}_{\max }(\mathrm{n}, \mathrm{b})=\max \left\{\mathrm{k}: 0 \leq \mathrm{k} \leq \mathrm{n}-\mathrm{b}, \mathrm{g}_{4}(\mathrm{n}, \mathrm{b})=\mathrm{G}(\mathrm{n}, \mathrm{k}, \mathrm{b})\right\}$,

$\ell_{\min }(\mathrm{n}, \mathrm{b})=\min \left\{\ell: 0 \leq \ell \leq \mathrm{n}-1, \mathrm{M}_{4}(\mathrm{n}, \mathrm{b})=\mathrm{F}(\mathrm{n}, \ell, \mathrm{b})\right\}$,

$\ell_{\max }(\mathrm{n}, \mathrm{b})=\max \left\{\ell: 0 \leq \ell \leq \mathrm{n}-1, \mathrm{M}_{4}(\mathrm{n}, \mathrm{b})=\mathrm{F}(\mathrm{n}, \ell, \mathrm{b})\right\}$,

with

$\mathrm{k}_{\min }(\mathrm{b}, \mathrm{b})=\mathrm{k}_{\max }(\mathrm{b}, \mathrm{b})=0=\ell_{\min }(\mathrm{b}, \mathrm{b})=\ell_{\text {min }}(\mathrm{b}, \mathrm{b})$ for all $\mathrm{b} \geq 1$.

Lemma 5.2.3 : For any $\mathrm{b}(\geq 1)$ fixed,

(1) $\mathrm{G}(3 \mathrm{~b}, \mathrm{k}, \mathrm{b})$ is uniquely minimized at $\mathrm{k}=\mathrm{b}$ with $\mathrm{g}_{4}(3 \mathrm{~b}, \mathrm{~b})=5 \mathrm{~b}$,

(2) $\mathrm{F}(2 \mathrm{~b}+1, \ell, \mathrm{b})$ is uniquely minimized at $\ell=\mathrm{b}$ with $\mathrm{M}_{4}(2 \mathrm{~b}+1, \mathrm{~b})=4 \mathrm{~b}+1$.

The solution of the bottleneck Reve's puzzle is open. However, we make below the conjecture about the solution of the puzzle.

Conjecture : For any $\mathrm{s}(\geq 1)$ and $\mathrm{b}(\geq 1)$ fixed,

(1) $\mathrm{G}\left(\frac{\mathrm{s}(\mathrm{s}+1)}{2} \mathrm{~b}, \mathrm{k}, \mathrm{b}\right)$ is uniquely minimized at $\mathrm{k}=\frac{\mathrm{s}(\mathrm{s}-1)}{2} \mathrm{~b}$ with

$$
\mathrm{g}_{4}\left(\frac{\mathrm{s}(\mathrm{s}+1)}{2} \mathrm{~b}, \mathrm{~b}\right)=\mathrm{b}\left[(\mathrm{s}-1) 2^{\mathrm{s}}+1\right]
$$

furthermore,

$$
\mathrm{g}_{4}\left(\frac{\mathrm{s}(\mathrm{s}+1)}{2} \mathrm{~b}+\mathrm{i}, \mathrm{b}\right)=\mathrm{b}\left[(\mathrm{s}-1) 2^{\mathrm{s}}+1\right]+\mathrm{i} 2^{\mathrm{s}} \text { for all } 1 \leq \mathrm{i} \leq(\mathrm{s}+1) \mathrm{b},
$$


(2) $\mathrm{F}\left(\left(\frac{\mathrm{s}(\mathrm{s}+1)}{2}-1\right) \mathrm{b}+1, \ell, \mathrm{b}\right)$ is uniquely minimized at $\ell=\frac{\mathrm{s}(\mathrm{s}-1)}{2} \mathrm{~b}$ with

$$
\mathrm{M}_{4}\left(\left(\frac{\mathrm{s}(\mathrm{s}+1)}{2}-1\right) \mathrm{b}+1, \mathrm{~b}\right)=\mathrm{b}(\mathrm{s}-1) 2 \mathrm{~s}+1
$$

moreover,

$$
\mathrm{M}_{4}\left(\left(\frac{\mathrm{s}(\mathrm{s}+1)}{2}-1\right) \mathrm{b}+\mathrm{i}+1, \mathrm{~b}\right)=\mathrm{b}(\mathrm{s}-1) 2^{\mathrm{s}}+\mathrm{i} 2^{\mathrm{s}}+1 \text { for all } 1 \leq \mathrm{i} \leq(\mathrm{s}+1) \mathrm{b} \text {. }
$$

Note that $b=1$ corresponds to the solution of the Reve’s puzzle (in $\$ 3.1$ ).

\subsection{The Four-in-a-Row Puzzle}

The four-in-a-row puzzle, introduced by Scorer, Grundy and Smith [19], is one with four pegs, and is the generalization of the three-in-a-row puzzle.

The puzzle is as follows : The four pegs, designated as $\mathrm{S}, \mathrm{P}_{1}, \mathrm{P}_{2}$ and $\mathrm{D}$, are arranged in a row. Initially, a tower of $\mathrm{n}(\geq 1)$ discs of different radii, labeled, $\mathrm{D}_{1}, \mathrm{D}_{2}, \ldots, \mathrm{D}_{\mathrm{n}}$, in increasing order of their radii rest on the source peg, $\mathrm{S}$, in standard position. Disc movements are allowed in either direction between the adjacent pegs only. The objective is to transfer this tower of $\mathrm{n}$ discs from the source peg, $\mathrm{S}$, to the destination peg, $\mathrm{D}$, in standard position, in minimum number of moves (under the conditions of the Tower of Hanoi).

In this case, there are three possibilities, as shown in the figure below.

Let $\operatorname{MFR}(n), \operatorname{MMFR}(n)$ and $\operatorname{MMMFR}(n)$ be the minimum number of moves required to transfer the tower of $\mathrm{n}$ discs from the peg $\mathrm{S}$ to the peg $\mathrm{D}$.

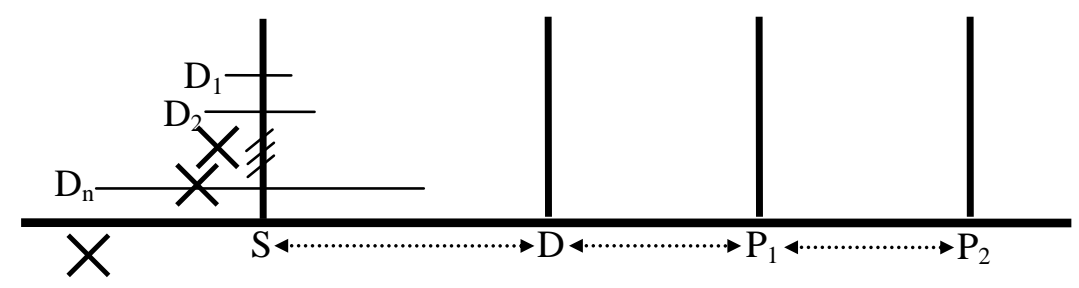

Case (1) : Disc movements are allowed between $S, D ; D, P_{1}$, and $P_{1}, P_{2}$

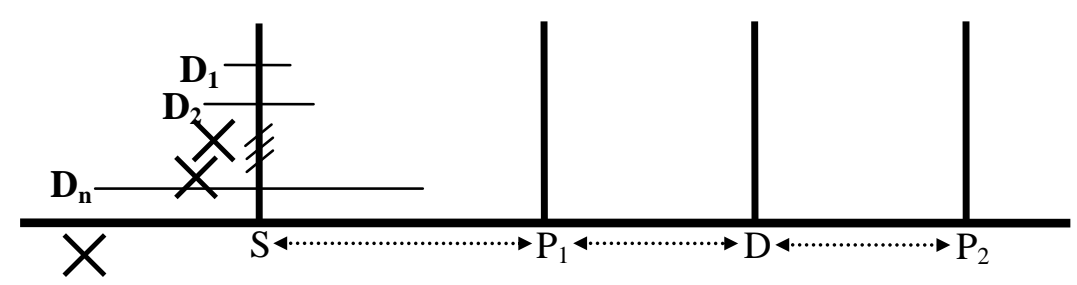

Case (2) : Disc movements are allowed between $\mathrm{S}, \mathrm{P}_{1} ; \mathrm{P}_{1}, \mathrm{D}$, and $\mathrm{D}, \mathrm{P}_{2}$ 


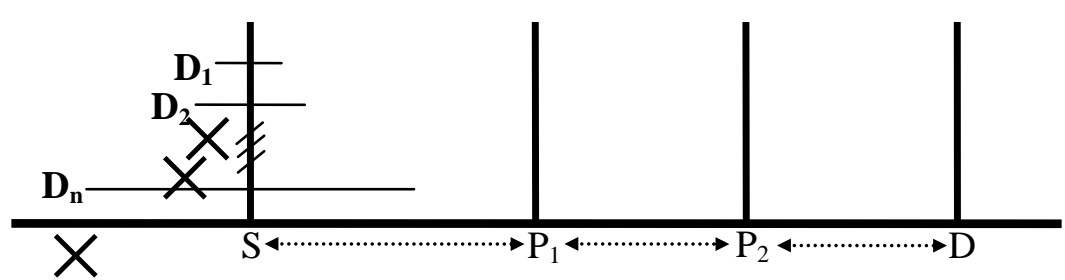

Case (3) : Disc movements are allowed between $\mathrm{S}, \mathrm{P}_{1} ; \mathrm{P}_{1}, \mathrm{P}_{2}$, and $\mathrm{P}_{2}, \mathrm{D}$

Proposition 5.3.1 : MFR(n) satisfies the following recurrence relation :

$\operatorname{MFR}(\mathrm{n})=\min \left\{\operatorname{MMMFR}(\mathrm{k})+\operatorname{MMFR}(\mathrm{k})+\frac{1}{2}\left(2^{\mathrm{n}-\mathrm{k}}-1\right)\right\}, \mathrm{n} \geq 3$,

$$
1 \leq \mathrm{k} \leq \mathrm{n}-1
$$

$\operatorname{MFR}(1)=1, \operatorname{MFR}(2)=4$.

Proposition 5.3.2 : MMFR(n) satisfies the following recurrence relation :

$\operatorname{MFR}(\mathrm{n})=\min \left\{\operatorname{MMMFR}(\mathrm{k})+\operatorname{MMFR}(\mathrm{k})+\left(3^{\mathrm{n}-\mathrm{k}}-1\right)\right\}, \mathrm{n} \geq 3$

$$
1 \leq \mathrm{k} \leq \mathrm{n}-1
$$

$\operatorname{MMFR}(1)=2, \operatorname{MMFR}(2)=6$.

It may be mentioned here that, it remains to prove that the schemes followed to find the recurrence relations satisfied by $\operatorname{MFR}(\mathrm{n})$ and $\operatorname{MMFR}(\mathrm{n})$ are indeed optimal. It also remains to find explicit forms of MFR(n) and MMFR(n).

The following table gives the expressions for MFR(n), MMFR(n) and MMMFR(n) for $\mathrm{n}=$ 1(1)6, where the last row is due to Stockmeyer [21].

\begin{tabular}{|l|c|c|c|c|c|c|}
\hline $\mathrm{n}$ & 1 & 2 & 3 & 4 & 5 & 6 \\
\hline MFR(n) & 1 & 4 & 9 & 18 & 29 & 44 \\
\hline MMFR(n) & 2 & 6 & 12 & 22 & 36 & 54 \\
\hline MMMFR(n) & 3 & 10 & 19 & 34 & 57 & 88 \\
\hline
\end{tabular}

\subsection{The Four-Peg Cyclic Puzzle}

The four-peg cyclic puzzle, due to Scorer, Grundy and Smith [19], is the four-peg generalization of the cyclic Tower of Hanoi.

In the four-peg cyclic puzzle, the four pegs, $S, \mathrm{P}_{1}, \mathrm{P}_{2}$ and $\mathrm{D}$, are arranged in a circle. Initially, a tower of $n(\geq 1)$ discs of different radii, labeled, $D_{1}, D_{2}, \ldots, D_{n}$, in increasing order of their radii rest on the source peg, $\mathrm{S}$, in standard position.

The objective is to transfer this tower of $\mathrm{n}$ discs from the source peg, $\mathrm{S}$, to the destination peg, D, in standard position, in minimum number of moves (under the additional conditions of the Tower of Hanoi). 
The puzzle itself has three versions, as shown in the figure below.
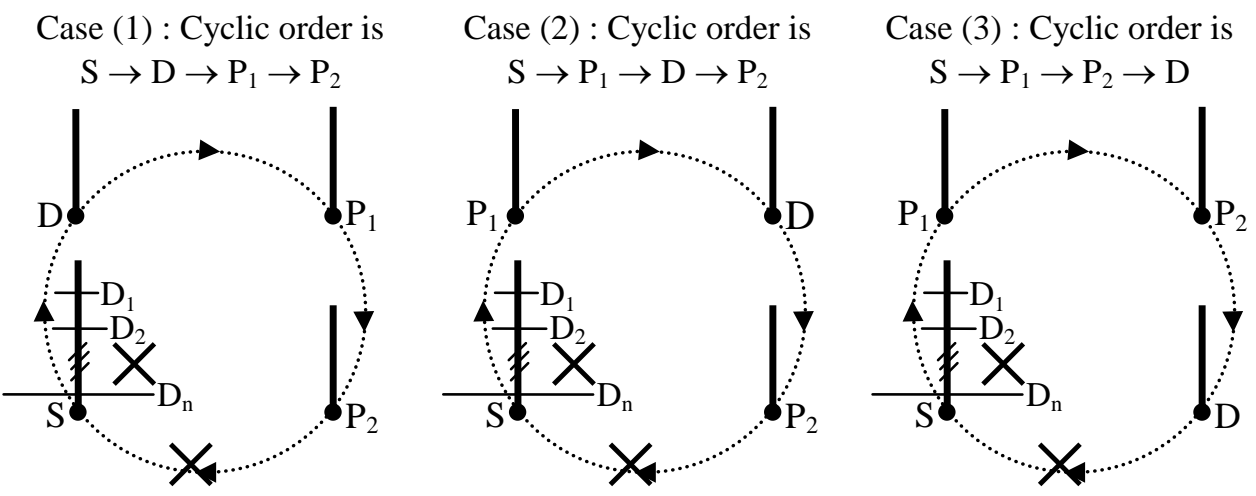

Figure : The Four-Peg Cyclic Puzzle

Let $\operatorname{MC}(n), \operatorname{MCC}(n)$ and $\operatorname{MCCC}(n)$ be the minimum number of moves required to transfer the tower of $n$ discs from the source peg, $\mathrm{S}$, to the destination peg, $\mathrm{D}$, corresponding to the three cases of the above figure. It still remains open to find the recurrence relations satisfied by $\mathrm{MC}(\mathrm{n})$, $\operatorname{MCC}(n), \operatorname{MCCC}(n)$.

\section{REFERENCES}

[1] Atkinson, M.D. The Cyclic Towers of Hanoi. Information Processing Letters, 13(3) (1981), 118 - 119.

[2] Dudeney, H.E. The Canterbury Puzzles. Thomas Nelson and Son, London (4 ${ }^{\text {th }}$. Ed. by Dover, 1958).

[3] Frame, J.S. Solution to AMM Problem 3918. American Mathematical Monthly, 48 (1941), 216-219.

[4] Gedeon, T.D. The Reve's Puzzle : An Iterative Solution Produced by Transformation. The Computer Journal, 35(2) (1992), 186 - 187.

[5] Hayes, P.J. A Note on the Towers of Hanoi Problem. The Computer Journal, 20(3) (1977), 282-285.

[6] Hinz, A.M. An Iterative Algorithm for the Tower of Hanoi with Four Pegs. Computing, 42 (1989), 133-140.

[7] Hinz, A.M. Shortest Paths Between the Regular States of the Hower of Hanoi. Information Sciences, 63 (1992), 173-181.

[8] Liefvoort, van de A. An Iterative Algorithm for the Reve's Puzzle. The Computer Journal, 35(1) (1992), 91-92.

[9] Lucas, E. Discours Prononce a la Distribution Solennelle des Prix, Faite la Mardi 4 Aout 1885. Lycee Saint Louis, Paris, 1885.

[10] Lucas, E. Recreations Mathematiques (Tome 3). Gauthier-Villars, Paris. 1893.

[11] Lunnon, W.F. The Reve's Puzzle. The Computer Journal, 29(5) (1986), 478.

[12] Lu, Xue-Miao. An Iterative Solution for the 4-Peg Towers of Hanoi. The Computer Journal, 32(2) (1989), 187-189.

[13] Majumdar, A.A.K. The Classical Tower of Hanoi Problem and Its Generalizations. Vol. 1 : Multi-Peg Generalization. Lambert Academic Publishing, Germany (2012).

[14] Minsker, S. The Little Towers of Antwerpen Problem. Information Processing Letters, 94 (2005), 197201.

[15] Minsker, S. The Towers of Antwerpen Problem. Information Processing Letters, 38 (1991), 107-111. 
[16] Poole, D. The Bottleneck Towers of Hanoi Problem. J. Recreational Mathematics, 24(3) (1992), $203-$ 207.

[17] Rohl, J.S. and Gedeon, T.D. The Reve's Puzzle. The Computer Journal, 29(2) (1986), 187-188.

[18] Roth, T. The Tower of Brahma Revisited. Journal of Recreational Mathematics, 7(2) (1974), 116-119.

[19] Scorer, J.S., Grundy, P.M. and Smith, C.A.B. Some Binary Games. The Mathematical Gazette, 280 (1944), 96-103.

[20] Stewart, B.M. Problem 3918. American Mathematical Monthly, 46 (1939), 363.

[21] Stockmeyer, Paul K. Variations on the Four-Post Tower of Hanoi Puzzle. Congressus Numerantium, 102 (1994), 3-12.

[22] Stockmeyer, Paul K. and Lunnon, W.F. New Variations on the Tower of Hanoi. $13^{\text {th }}$ International Conference on Fibonacci Numbers and Their Applications, July 2008, Greece. p. 1-8.

[23] Wood, D. The Towers of Brahma and Hanoi Revisited. J. Recreational Mathematics, 14(1) (1981-82), 17-24.

[24] Wood, D. Adjudicating a Towers of Hanoi Contest. International Journal of Computer Mathematics, 14 (1983), 199-207.

[25] Wu, J.S. and Chen, R.J. The Towers of Hanoi Problem with Parallel Moves. Information Processing Letters, 44(5) (1992), 241-243.

[26] Wu, J.S. and Chen, R.J. The Towers of Hanoi Problem with Cyclic Parallel Moves. Information Processing Letters, 46(1) (1993), 1-6. 